\title{
A prática pedagógica e o professor do ensino superior: desafios enfrentados e vivências construídas
}

\author{
Sirlei de Lourdes Lauxen ${ }^{1}$
}

\begin{abstract}
Resumo
O presente texto versa sobre a docência no ensino superior e, nela, a prática pedagógica dos professores da área da Saúde. O objetivo da investigação apresenta como intenção analisar as práticas dos docentes, identificando o espaço da aula como lócus da aprendizagem. A metodologia qualitativa, por meio de um Estudo de Caso, teve, como instrumentos de pesquisa, questionários semiestruturados e entrevistas com oito professores da área da Saúde. A análise dos dados coletados referente aos saberes presentes na prática do professor, bem como a organização da aula como espaço de aprendizagem, dá-se a partir do agrupamento das respostas, pela sua proximidade e pelo entrelaçamento entre elas. No estudo, fica evidente que os saberes pessoais, pedagógicos e experienciais fazem parte da prática dos professores; pela ação/ reflexão/ação das vivências em aula, é possível melhorar e avançar nas mudanças necessárias às melhorias e à qualidade na educação do ensino superior, através da formação pedagógica em serviço.
\end{abstract}

Palavras-chave: Prática pedagógica; formação pedagógica; saberes; docents; ensino superior.

1 Universidade de Cruz Alta. Doutora em Educação / UFRGS. Professora do PPG em Práticas Socioculturais e Desenvolvimento Social/Unicruz. Líder do Grupo de Pesquisa Núcleo de Estudo e Pesquisa em Práticas Socioculturais. s.lauxen@hotmail.com 


\title{
Teaching practice and the higher education teacher: challenges faced and built experiences
}

\begin{abstract}
This paper analyzes the teaching in higher education and in it as well the pedagogical practice of teachers in the health care area. The goal of the research is to analyze the practices of teachers identifying the space of class as learning locus. The qualitative methodology through a Case Study had as research tools semistructured questionnaires and interviews with eighteen teachers in the health area. The analysis of the collected data referring to the knowledge present in the teacher's practice, and the organization of the class as a learning space takes place from the pool of responses by their proximity and the entanglement between them. In the study it is clear that personal knowledge, educational, experiences are part of the teachers practice and for the action/ reflection/action of the experiences in the classroom, can improve and advance the necessary changes to the improvements in the quality in higher education, through educational in-service training.
\end{abstract}

Keywords: Pedagogical practice; teacher training; teaching; knowledges; higher education.

\section{Na introdução: a questão se apresenta}

Um dos temas recorrentes nas discussões sobre o ensino superior nos últimos anos tem sido a docência, e, nela, a prática pedagógica dos professores em aula. Objeto de muitas pesquisas nas instituições de educação superior, pelo fato de ser complexo, exige a continuidade das investigações e rigorosidade nas reflexões sobre o assunto. Isso porque, ao tratar da qualidade da formação profissional, a mesma tem relação direta com o papel que o professor desempenha em aula.

Na construção da aula, cada docente se envolve com inúmeras atividades em situações específicas de ensino e de aprendizagem, as quais 
exigem, para cada momento, uma atuação que atenda à demanda da situação. Para dar conta da sua função, articula um conjunto de saberes necessários à efetivação da prática.

Cabe questionar os saberes presentes/necessários na prática do professor do ensino superior, bem como se a aula está ou não se constituindo em espaço de ensino-aprendizagem, considerando-se que, na maioria das vezes, apesar de ter a formação stricto sensu, o professor inicia sua docência sem ter a formação pedagógica para tal. Nessa perspectiva, a investigação teve como objetivo analisar as práticas dos docentes do ensino superior, identificando o espaço da aula como lócus da aprendizagem. O recorte deu-se na área da Saúde de uma instituição comunitária ${ }^{2}$, por representar um espaço significativo de possibilidades, tanto na perspectiva de melhorias como na busca por inovação. Para orientar as discussões, o embasamento teórico percorre as concepções de Tardif, Pimenta e Anastasiou, Masetto, Cunha e Nóvoa, sobre o cotidiano da sala de aula universitária, bem como estabelece relações entre a formação pedagógica e a prática, como uma ação que vai se construindo no dia a dia do professor.

A metodologia, de cunho qualitativo, realizou-se a partir de dados colhidos com oito docentes, sendo dois de cada um dos cursos: Biomedicina, Enfermagem, Fisioterapia e Farmácia. Para a seleção do grupo, o critério utilizado foi o de trabalhar há mais de dois anos na instituição, ser professor efetivo e demonstrar interesse em participar da pesquisa. Do total, sete eram do sexo feminino, e um, do masculino; seis possuíam regime de trabalho em tempo integral, e dois, em tempo parcial; seis deles, titulação de mestre, e dois, doutores. Cinco dos entrevistados tinham de dois a cinco anos de trabalho, um, nove anos, e dois, entre doze e dezoito anos.

Importante salientar que todos os professores, com idade entre $25 \mathrm{e}$ 48 anos, tinham a titulação de mestre e doutor há menos de três anos. Seis dos professores atuam somente na Instituição, mas já tiveram outras experiências profissionais, e dois realizam outras atividades.

2 Instituições Comunitárias de Educação Superior (ICES) instituídas pela Lei nº 12.881, de 12 de novembro de 2013. 
Os instrumentos de pesquisa, questionário semiestruturado e entrevistas ${ }^{3}$, foram respondidos por todos os pesquisados. O questionário semiestruturado, com perguntas fechadas e abertas, apresentou questões referentes à identificação, à titulação e ao percurso profissional. As entrevistas, realizadas com data e hora marcadas, garantiram ao entrevistado um diálogo menos dirigido, com a possibilidade de discorrer sobre o tema proposto, sem condições pré-fixadas. A análise dos dados coletados, referente aos saberes presentes na prática do professor, bem como a organização da aula como espaço de aprendizagem, dá-se a partir do agrupamento das respostas, pela sua proximidade e pelo entrelaçamento, considerando-se dois eixos: os desafios enfrentados na prática da aula e as possibilidades geradas.

\section{Na prática pedagógica: os desafios enfrentados}

A docência universitária constitui-se um grande desafio. Desafio, pela complexidade que é o exercício de ser professor, pelo fato de não existir nenhuma exigência legal de formação específica nesse nível de ensino e por, ao mesmo tempo, exigir desse profissional os saberes que necessitam ser vivenciados na sua prática pedagógica e para os quais não teve formação.

O movimento da prática parece ser determinado pela visão de conhecimento/instituição e de ensino/aprendizagem de cada professor. Para a Universidade de Cruz Alta, instituição comunitária localizada no Noroeste do Rio Grande do Sul, a aula está definida e é compreendida como

[...] uma oportunidade de interação entre os sujeitos que, através da linguagem, enquanto meio, produz conhecimento. Os sujeitos da aula são, tanto os professores, com os conhecimentos produzidos no âmbito da ciência que praticam, quanto os estudantes com os saberes e conhecimentos que trazem para a aula (UNIVERSIDADE DE CRUZ ALTA, 2013, p. 32).

3 Os questionários semiestruturados e as entrevistas dos professores estão identificados no texto pela sigla Doc e pelos números 1, 2,3, até o 8 . 
Para o curso de Farmácia, a aula possui

[...] um dos objetivos de aprendizagem, fundamentais aos cursos de graduação, é o de aprender a aprender, que ao acadêmico de Farmácia deverá ser possibilitado o desenvolvimento de busca, seleção e avaliação crítica de dados e informação e atividades de práticas laboratoriais que deem suporte à sua futura ação profissional como agente de transformação da realidade (UNIVERSIDADE DE CRUZ ALTA, 2012, p. 19, grifos nossos).

Nos cursos de Biomedicina, Enfermagem e Fisioterapia, em síntese, as aulas devem considerar a realidade constituída, partindo de suas vivências cotidianas e possibilitando a construção de conhecimentos reais. Para compreender esse processo de vivências e experiências, os professores foram indagados, durante a entrevista, sobre diversas questões em relação à docência, as quais estão apresentadas ao longo do texto. Dentre elas, quando perguntados sobre como são as aulas, como acontecem e por que acontecem dessa forma, as respostas estão colocadas como se expõe no Quadro 1.

\section{Quadro 1 - Depoimentos: desafios e experiências dos professores}

“[...] geralmente, eu faço aulas expositivas e, durante as aulas expositivas, eu já vou colocando algumas situações, alguns casos clínicos, pra jogar para a prática. Porque o aluno já vem condicionado a ter aula expositiva. E, se ele não tem, não recebe as coisas prontas; muitos não gostam de procurar, de pensar. Acho importante trabalhar bastante com pesquisa. Faço seminários também" (Doc. 4).

“A relação que eu tenho de feedback do aluno vai interferir no meu planejamento. Eu não consigo, por exemplo, programar uma aula e aquela aula ser sempre a mesma. Por quê? Porque cada turma tem sua característica, cada aluno tem uma forma de aprendizado" (Doc. 2).

"Eu tenho tentado fazer com que o aluno procure o conhecimento através do que eu falo e proporciono a eles. Mas eu não quero ser uma transmissora de ideias ou conteúdos. Então, a visão que a gente tem é fazer com que o aluno, a partir do que se tem de proposta, siga em busca do conhecimento. E, nas minhas disciplinas, eu consigo fazer isso" (Doc. 7).

Fonte: Dados da pesquisa

Percebe-se, na fala dos professores, que a aula expositiva $x$ aula 
prática, divisão da aula em vários momentos, seminários, planejamento, a partir das necessidades da turma, ganham significado, tornando-se o núcleo central; são denominadas, por Tardif e Lessard (2008), de espaço celular, constituídas, em locais organizados, por uma estrutura física, social e normativa. Quando o professor diz "utilizei como modelo as aulas que tive na graduação e, após, mudei quando eu iniciei na Unicruz, a partir dos encontros pedagógicos" (Doc. 5), deixa claras duas questões: a primeira, sobre a importância dos saberes pedagógicos; a segunda, sobre a importância da discussão coletiva pela Pedagogia Universitária. Outra questão explícita é o fato de o Doc. 2 ter feito especialização em docência no ensino superior antes de fazer o mestrado. Na sua fala, percebe-se um olhar abrangente para a turma e, ao mesmo tempo, individualizado, para cada estudante. Doc. 4, cujo doutorado foi concluído recentemente, apresenta preocupação com a pesquisa.

Ainda há a necessidade de se realizar na prática aquilo que se priorizou como importante e necessário nos planejamentos. A aula expositiva predomina, seja pela dificuldade dos acadêmicos de realizarem investigações, seja pela dificuldade do docente em construir propostas para além da aula expositiva. Muitas vezes, a aula expositiva se torna uma tranquilidade para o estudante, porque ele se comporta como sujeito passivo; também o é para o professor, porque pode lhe dar mais segurança em relação ao que vai ser trabalhado, não permitindo que o acadêmico possa adentrar em situações que ultrapassem seus saberes.

Ao mesmo tempo, no decorrer da sua trajetória profissional, o professor vai se construindo e se reconstruindo com novos conhecimentos e experiências. Experiências estas que se iniciam quando do ingresso do docente na escola e que, segundo Nóvoa (2008), vai se tornando "objeto e sujeito" da sua formação, possibilitando que, na discussão, na reflexão e na análise, individual ou coletiva, possa vivenciar uma prática que contemple as transformações que se processam na sociedade e que interferem no dia a dia do seu trabalho.

Segundo Nóvoa (1992), a experiência é inerente ao cotidiano do professor e não está vinculada ao tempo de serviço, mas sim ao que acontece com o profissional no tempo e no contexto do espaço escolar 
onde atua. Os docentes investigados apresentam algumas situações relevantes que enfocam o processo de constituição da prática, bem como os saberes que evidenciam/predominam no dia a dia da aula universitária. Essas situações estão identificadas como dificuldades e facilidades, independente do tempo de experiência.

O relato sobre as primeiras impressões, no início da docência, deixa claras as dificuldades:

\section{Quadro 2 - Depoimentos: dificuldades enfrentadas no trabalho docente}

\begin{tabular}{|} 
“Bom, acho que as dificuldades se deram principalmente no preparo das aulas. Quando \\
a gente está iniciando, não imagina quanto trabalho dá: a busca de material, a pesquisa \\
diária, o preparo de aulas práticas, a própria busca por atualização em congressos, em \\
artigos científicos, em livros novos e atualizados [...] Fica-se três, quatro dias preparan- \\
do para que, numa manhã, consiga dar aquela aula" (Doc. 1). \\
"Quando eu iniciei, a dificuldade maior era a questão de não ter o material. [...] de \\
estruturar a sequência da aula. [...]" (Doc. 3)." \\
$\begin{array}{c}\text { "[...] um pouco de insegurança; de repente, é muito mais fácil despejar o conteúdo e ir } \\
\text { embora do que se estruturar de forma que eles consigam aprender" (Doc. 6). }\end{array}$
\end{tabular}

Fonte: Dados da pesquisa

Os depoimentos transcritos ressaltam como maior dificuldade a preparação das aulas e colocar-se com postura de professor, o que demonstra a falta de formação pedagógica, já apontada pelos entrevistados. Ainda, dos oito professores que fizeram parte da pesquisa, metade deles, antes de iniciar ou de terminar o stricto sensu, passou a trabalhar com a docência sem ter tido nenhuma formação pedagógica durante seus estudos, o que pode ter contribuído para essas dificuldades, pois saíram da graduação e iniciaram a docência. Cunha (2008a) coloca, inclusive, que, nessa concepção clássica de universidade, dificilmente faça parte das propostas e dos projetos institucionais a orientação aos saberes próprios de ensinar e de aprender.

Em relação às facilidades, as falas apresentam-se da seguinte maneira: 


\title{
Quadro 3 - Depoimentos: facilidades encontradas no trabalho docente
}

\begin{abstract}
"Olha, sobre as facilidades, eu sempre fui muito comunicativa, sempre me dei muito bem com as pessoas. [...] Então, eu acho que, nesta questão de relacionamento, eu sempre me dei muito bem com os alunos" (Doc. 4).

"Facilidades eu tive no contato com os alunos; não tenho dificuldade de trabalhar com uma turma. Eu acho que a principal facilidade é esta" (Doc. 1).

“A facilidade que eu tive foi no início do trabalho. Eu já tinha mais ou menos uma sequência, só precisava adaptar e melhorar o que tinha que ser melhorado. Então, foi esta a facilidade maior que eu tive" (Doc. 6).
\end{abstract}

Fonte: Dados da pesquisa

Dos relatos mencionados, a comunicação é o elemento principal trazido pelos professores como facilidade para a realização do seu trabalho. Esse saber, que, segundo Tardif (2002), faz parte dos saberes pessoais dos professores, tem como fonte social de aquisição a família e o ambiente de vida. Integram-se no trabalho docente pela história de vida de cada um e pela socialização com o grupo de alunos, o que se demonstrada nos excertos das falas: "sempre fui comunicativa" e "no contato com os alunos".

Segundo Pimenta e Anastasiou (2002), não há modelos ou experiências a serem aplicados na profissão de professor. Ele deve se referenciar em sua experiência, partindo de um processo de reflexão, tanto individual quanto coletivo, que leve à autocrítica salutar, o que ainda não se percebe no grupo entrevistado. A utilização de suas experiências docentes anteriores, positivas ou não, é um primeiro passo para se tornar um profissional da educação que, diante das exigências de sua atuação, constrói ações que possibilitem sua autonomia.

Pela fala dos professores, é possível constatar que a prática não pode ficar reduzida à comprovação da teoria ou à sua execução normativa. A prática constitui a sustentação e a possibilidade de recriação da teoria. Esse trânsito prática/teoria/prática, no território do ensino universitário, requer a pesquisa como princípio educativo - a dúvida - para questionar o conhecimento sistematizado - oficialmente institucionalizado - no enfrentamento com a leitura da realidade, na superação da extensão 
como atividade assistencial e isolado do ensino e da pesquisa.

Considerar como parte da prática pedagógica o ensino articulado à pesquisa e/ou à extensão, compreender as possibilidades que a realidade apresenta, por meio de questões cotidianas que podem ser inseridas na aula e, a partir daí, investigadas, ainda são tarefas complicadas para a maioria dos professores entrevistados, pela dificuldade em transitar nesse caminho com clareza e segurança.

Entre as dificuldades e facilidades, ao se referirem ao trabalho com a pesquisa, ou mesmo à articulação entre ensino, pesquisa e extensão, os professores colocam:

\title{
Quadro 4 - Depoimentos: dificuldades e facilidades em relação ao ensino, pesquisa e extensão
}

\begin{abstract}
"Sim, a gente pega tópicos. Pegamos, por exemplo, o colesterol, enzimas hepáticas, e aí a gente cria. Quando se quer trabalhar com uma determinada droga e quer saber se aquela droga tem pato-toxicidade, se intoxica um rato com esta droga e depois vai medir estas enzimas hepáticas. Só que aí, durante os experimentos, começam a ver que os resultados podem dar alterados. Vão verificar por que os resultados estão alterados, começam a visualizar os sintomas, ver os resultados bioquímicos e como relacionar. Eu acho que a prática da pesquisa é mais importante porque faz com que o aluno vivencie"
\end{abstract} (Doc. 4).

"[...] as disciplinas que apresentam questões amplas ou que envolvem um contexto geral de saúde é perfeitamente possível. A gente organiza atividades, faz visitas a postos de saúde, faz visitas a outras instituições, e - a partir até mesmo dos artigos - vai formulando questões de pesquisa" (Doc. 6).

"Olha, com muito esforço. Eu tento colocar a pesquisa na sala de aula e, muitas vezes, sou considerada chata. Das minhas disciplinas, saí com proposta de trabalho para os alunos falando 'isso aqui é motivo para fazermos uma pesquisa'. Entendo que a pesquisa é importante para a prática profissional. Estou sempre fundamentando as aulas e fortalecendo este pensamento, apesar de muitos alunos serem contrários. Eles têm dificuldade em aceitar esta proposta" (Doc. 3).

“Eu vejo que dá para associar o ensino com a pesquisa. Na nossa área, não existem pesquisadores, ou melhor, pesquisas em grande quantidade, como a gente vê nas outras áreas. Então, qualquer coisa que se levantar na realidade de qualquer comunidade, de qualquer população, de qualquer grupo sobre a questão alimentar é relevante e pode se fazer pesquisa" (Doc. 7).

Fonte: Dados da pesquisa

Segundo Chizzotti (2004), o ensino precisa apoiar-se na pesquisa, e só vai ganhar significado quando propiciar o prazer de descobrir, quando 
provocar a observação, mobilizar a curiosidade, esclarecer dúvidas e orientar as ações. O que precisa ficar claro é que a pesquisa não supõe só laboratórios, meios tecnológicos, verbas, mas também uma atividade cotidiana que compreenda, de forma abrangente, os atos, os fatos, a realidade e o contexto onde estiverem inseridos.

Veiga (2004) coloca que aprender a pesquisar deve fazer parte do cotidiano da instituição educativa e, principalmente, da sala de aula. Segundo ela, a ação educativa é precedida por algum tipo de investigação, e esta é feita com o objetivo de produzir conhecimento.

Nesse sentido, o papel do professor é criar condições para que os estudantes aprendam a pesquisar, motivando-os e instrumentalizando-os para que assumam a experiência educativa como fonte de conhecimento. Conforme se observa, ainda permanece, independente do tempo de serviço ou da titulação, o desafio de a pesquisa fazer parte da prática cotidiana no ensino da graduação.

O ensino indissociado da pesquisa e da extensão, ou seja, um ensino na perspectiva da produção do conhecimento, realizado por todos os envolvidos, faz da universidade lócus de construção de conhecimento, tanto para o acadêmico quanto para o professor. A extensão, conforme Masetto (1998), torna-se um campo sociocultural no qual a universidade se insere e no qual intervém para aprender e para ensinar, recriando teorias, criando novas teorias e, sobretudo, fazendo, das salas de aulas, aulas vivas.

Exige-se que o docente considere a indissociabilidade entre o ensino, a pesquisa e a extensão como fundamento metodológico; que considere o contexto universitário como espaço de construção do conhecimento, de investigação, de reflexão e de diálogo entre situações do cotidiano e os conhecimentos sistematizados; que ele saiba por que, para que e como trabalhar com o estudante na e sobre a realidade; mas não existe a exigência da preparação para adentrar no ensino superior.

Doc. 5, com titulação de doutor e tempo de serviço de menos de três anos, apresenta um depoimento importante sobre seu entendimento de pesquisa, ao iniciar seu trabalho, e a mudança que teve de processar na sua prática pedagógica, na medida em que percebeu que a sua concepção 
de pesquisa era diferente da que já se procurava realizar na Instituição:

[...] sobre a questão da pesquisa. Quando eu iniciei a trabalhar aqui, eu não me sentia preparada para trabalhar com uma pesquisa, porque a pesquisa que eu estava acostumada a trabalhar era diferente. A Unicruz tem uma visão mais social, então a pesquisa tem que estar voltada mais para o social, diferente da que eu utilizava antes. A minha pesquisa era de bancada, dentro de um laboratório, eu trabalhando com meu orientador e com algum aluno. Aqui não. Para trabalhar o perfil que a universidade deseja, além do laboratório, tem que relacionar com questões da sociedade (Doc. 5).

O que o professor aponta está presente nos documentos oficiais da Universidade de Cruz Alta, cujas diretrizes relacionadas à pesquisa mostram "a preocupação com o bem comum, um dos elementos integrantes das linhas de pesquisa da Instituição, exigindo que a mesma se insira na comunidade como forma de desempenhar sua função social e contextualizar os assuntos abordados" (PPPI, 2007, p. 51). A fala do professor é significativa, porque comprova que essa mudança ocorre após o seu ingresso na Universidade, e quando estava sendo construído o Projeto Pedagógico da instituição. Isso reforça duas questões: a primeira, que a participação nas discussões e decisões compromete o sujeito que dela participa; a segunda, que se reforça, na caminhada, a construção coletiva.

A incursão pelos saberes docentes e a forma como estão presentes na prática pedagógica universitária constatam a emergência de aprofundamento dos estudos nessa direção, principalmente pela relevância de ter presente que uma aula vai muito além dos conteúdos trabalhados. Isso exige do profissional outros saberes importantes para o ensino-aprendizagem.

\section{No espaço da aula: ações construtivas}

Apesar das dificuldades enfrentadas, percebe-se o interesse em querer realizar um trabalho em que o ensino-aprendizagem aconteça pela ação/ reflexão/ação. O mesmo está presente quando explicitam sobre os pontos 
destacados a seguir.

A mudança da/na prática pedagógica, desde que iniciou a docência, e a forma como isso aconteceu foi enfatizado por Doc. 4:

Eu acho que melhorei bastante. Hoje, olho uma aula que preparei no primeiro semestre e comparo com uma aula que eu preparei agora, nos últimos semestres. Muitas vezes retomo uma aula já trabalhada, verifico outras formas de explorar. Estou indo para um caminho diferente e os alunos estão entendendo melhor. Eu acho que melhorei [...] (Doc. 4).

Cada vez mais fica clara a ideia de que atuar numa sala de aula, na qual geralmente a diversidade é a característica predominante, exige domínio de conhecimento e de aportes didáticos. Observa-se que os professores pesquisados, aos poucos, vão construindo uma concepção sobre a forma como atuar, lançando mão, para isso, do saber experiencial até então vivenciado. De uma maneira geral, seus saberes iniciais são considerados verdadeiros, pois não são confrontados com outros; é seu conhecimento, sua prática e sua teoria didática fora da sala de aula. À medida que há uma prática reflexiva, uma formação continuada, seja stricto sensu ou por encontros pedagógicos, os docentes vão construindo uma identidade e qualificando seu fazer.

Percebe-se que muitos buscam uma articulação entre o que já conhecem e o que ainda não conhecem. Isso quer dizer que buscam articular saberes e conhecimentos sobre a formação acadêmica com os saberes e conhecimentos da experiência. Na verdade, dentro do papel atual do professor, a busca por um aprimoramento profissional e bemsucedido deve envolver, além de uma adequada formação teórica e pedagógica, habilidade específica para fazer com que os estudantes percebam e reflitam sobre a realidade que os rodeia.

A sala de aula, ambiente rico em relações humanas, é aspecto fundante na prática educativa. Sua gestão e a relação entre estudantes e docentes levam o educador a pensar melhor sobre o que realiza. A atenção à necessidade dos acadêmicos passa pela responsabilidade de ultrapassar o simplismo, despertando seu pensamento crítico, para que entendam melhor sua condição humana, " afinal nossa presença no mundo não é a 
de quem se adapta, mas a de quem nele se insere. É a posição de quem luta para não ser apenas objeto, mas sujeito da história" (FREIRE, 1997 p. 54).

A esse respeito, é possível identificar a prática na relação professorestudante: os entrevistados têm consciência crítica de seu papel como docentes do ensino superior, dos princípios que devem fundamentar a sua prática, em relação aos compromissos que ela requer. Também nessa consciência uma propositura do trabalho docente é a busca pela construção da cidadania, capaz de fazer com que o sujeito seja construtor da cultura em suas múltiplas dimensões. Através da ação e do discurso, é estabelecida a busca pela recuperação do seu espaço, no qual se reconhecem como sujeito coletivo e, portanto, político.

Nesse processo, a relação com os estudantes desnuda-se, e os apontamentos dos docentes foram interessantes:

[...] é uma boa relação. Eu sinto que eles são bem receptivos comigo. Existem turmas que são mais fáceis de lidar que outras. Eu procuro ser ponderada - claro que às vezes a gente perde a paciência - mas procuro sempre conversar, trabalhar um pouco mais as questões de humanidade; e não só conhecimento técnico. Porque eu acho que a pessoa, o profissional é uma soma de fatores: é o intelectual, é o emocional, é psicológico, são as relações humanas. Hoje em dia, não se quer o profissional só técnico, se quer um profissional humanizado. A profissão exige isso. (Doc. 4).

Eu tenho uma relação muito próxima com os alunos. Às vezes, mesmo fora da sala de aula ficamos falando sobre saúde, sobre o enfermeiro, sobre a formação, sobre a postura o enfermeiro hoje. Tenho discutido muito isso (Doc. 2).

Sabe-se que a docência tem como objeto a interação humana, entre e para os seres humanos, no processo de ensino-aprendizagem, sendo, para isso, fundamental a relação professor-estudante. Esta relação e o ensino-aprendizagem foram historicamente se construindo no debate da didática, ora por uma relação autoritária, disciplinar, ora favorecendo a abertura, a flexibilidade, com a perda ou não dos saberes específicos, ora ampliando-se num processo de gestão coletiva e democrática dos conteúdos, dos saberes e das práticas, ora articulando o sentido educativo 
e instrucional dessa relação.

Ao destacarem a relação com os estudantes como ponto importante na prática pedagógica e como desafio a ser construído no trabalho, vão desnudando e compreendendo o significado de ser um bom professor. Nesse sentido, acrescentam a referencialidade do bom professor. As características importantes para um bom professor, segundo o grupo investigado, estão assim definidas:

Primeiramente, o professor tem que se comunicar bem. Segundo, precisa ter a intuição, para saber se a maneira como está trabalhando a disciplina está levando ou não o aluno a compreender, a gostar, a se interessar. [...]. O professor deve ter um bom conhecimento, deve fazer pesquisa, - não só decorar o que tem nos livros - deve também ter experiência na sua área para enriquecer o trabalho que realiza (Doc 4).

[...] a pessoa precisa ter uma identidade. Se quer ser respeitada tem que respeitá-los; se quer que eles acreditem, tem que ser honesta, verdadeira, autêntica. Muitas vezes não é necessário falar, a própria maneira de agir te revela e eles vão se espelhar (Doc. 4).

O professor deve ser disciplinado. Ensinar o aluno a ser responsável e ensinar bem o conteúdo. Fazer com que ele tenha vontade de aprender. $\mathrm{O}$ professor tem que ser um motivador dentro da sala de aula. Motivar o aluno a estudar. É um desafio (Doc. 5).

Um bom professor deve ter uma visão geral do seu trabalho e da sua profissão. Precisa fazer uma análise da realidade. Dentro da nutrição, precisamos ter presente os problemas sociais - a questão da fome, da pobreza, da própria produção do alimento. $\mathrm{O}$ professor hoje tem que fazer relações com a vida, com o dia a dia. Não pode ficar só voltado ao conteúdo, precisa ter a dimensão do mundo. Desde que eu me formei, coisas que eu aprendi na época, hoje são completamente diferentes (Doc. 7).

Todos os professores, tanto os de início de carreira quanto os com mais de dez anos na Instituição, ressaltam, nas considerações apresentadas, a importância da boa comunicação com o estudante e o conhecimento; a pesquisa, a motivação do aluno para a aprendizagem e a visão da realidade na qual estão inseridos.

Destaca-se, sobre o bom professor, a reflexão de Cunha (2000), de 
que o ambiente de onde se originou a pessoa do professor tem influência direta em seu comportamento. $\mathrm{O}$ aspecto humano, principal influência da formação pessoal, também conta como ponto primordial na formação e, consequentemente, na ideia de ser bom professor. Conforme a autora, não há receita específica para isso.

Nas discussões sobre o bom professor, uma das implicações nessa relação é a emocional, porque os professores se apresentam, no dia a dia, no espaço de trabalho, carregados de afeto e sentimentos diversos. Por isso, "os docentes devem ser formados, não só para uma relação pedagógica com os alunos, mas também para uma relação social com as "comunidades locais'" (NÓVOA, 2008, p. 229).

No questionário semiestruturado, foi pedido que enumerassem, por ordem de importância de um a quatro (um, como mais importante), a resposta à seguinte questão: para ser professor competente na contemporaneidade, o que é preciso? Dos oito professores, seis colocaram a mudança de postura para a função do ensino, deixando de ser mero transmissor do conhecimento; dois deles colocaram essa resposta em terceiro lugar. Nas outras respostas, tem-se: ter formação e profissionalização baseadas na exigência de preparo reflexivo, ao invés de técnico; possuir o conhecimento pedagógico do conteúdo a ser ensinado; compreender, para saber como e quando as tecnologias podem ser aplicadas na educação; todas elas divididas quanto à ordem de importância.

De acordo com Tardif (2002), o aperfeiçoamento da docência universitária exige integração de saberes. Diante desses novos desafios, o domínio restrito de uma área científica do conhecimento não é suficiente. O professor precisa desenvolver também um saber pedagógico e um saber político que lhe possibilitem a construção de uma ação educativa capaz de desenvolver consciência numa sociedade globalizada, complexa e contraditória. Dessa forma, docentes e discentes fazem-se sujeitos da educação. O saber-fazer pedagógico, por sua vez, possibilita ao educando a apreensão e a contextualização do conhecimento científico elaborado. Nessa direção, os argumentos são de que: 
Nos processos de formação de professores, éfdg preciso considerar a importância dos saberes das áreas de conhecimento (ninguém ensina o que não sabe), dos saberes pedagógicos (pois ensinar é uma prática educativa que tem diferentes e diversas direções de sentido na formação do humano), dos saberes didáticos (que tratam da articulação da teoria da educação e da teoria de ensino para ensinar nas situações contextualizadas), dos saberes da experiência do sujeito professor (que dizem do modo como nos apropriamos do ser professor em nossa vida) (PIMENTA; ANASTASIOU, 2002, p. 71).

Segundo as autoras, esses saberes se dirigem às situações de ensinar, e com elas dialogam, contribuindo no processo de revisão, de redirecionamento, de transformação, fazendo parte da formação do professor universitário, já que os professores, quando chegam à docência na universidade, mesmo que não seja pelo stricto sensu, trazem consigo variadas experiências do que é ser professor, adquiridas como alunos de diferentes professores ao longo de sua vida escolar e que lhes possibilitam dizer quais eram bons professores, quais eram bons em conteúdo, mas que não tinham uma prática pedagógica condizente.

O que preocupa ainda é a fala de alguns professores de educação superior de que basta o domínio do conhecimento específico, a prática profissional vivenciada na sua área de conhecimento e certo dom para dar aulas. Daí a fundamental importância de se levar o docente de ensino superior, objeto central das preocupações deste estudo, a refletir sobre sua prática profissional.

Ao pensar na sua prática e querer melhorá-la, o professor realiza uma ação que poderá ter consequência no seu desenvolvimento como ser humano político-cultural e social. Muitas vezes, isso requer que o docente reconsidere valores e descubra novas possibilidades de interagir com o novo e com o outro.

A relação com a comunidade mencionada na fala dos professores é uma das questões que fazem parte do Projeto Político-Pedagógico Institucional da Universidade de Cruz Alta (2007), e sua efetivação dáse também pelos seus cursos. A área da Saúde constitui-se numa das possibilidades da integração se efetivar de forma mais concreta. Por outro lado, é mais um desafio, apesar de Nóvoa (2008) colocar essa questão 
como um dilema da profissão do professor, ao dizer que, "em nossos dias, todos os discursos insistem na necessidade para os docentes de reconstruir um laço forte com o espaço comunitário" (NÓVOA, 2008, p. 227). Visto como dilema ou desafio, o importante é fazer com que a comunidade acadêmica desses cursos da área da Saúde compreenda e redefina o sentido social do seu trabalho na relação com a comunidade, principalmente pelas atividades de pesquisa e de extensão.

Alguns já identificaram e conseguem fazer essa articulação do trabalho em aula com a comunidade, mostrando, dessa forma, as possibilidades interdisciplinares. Essa constatação pode ser percebida pela fala do Doc. 3 , quando explicita a relação com os estudantes, inclusive em outros espaços de trabalho, nessa interface com a comunidade:

[...] eu participo do Conselho Municipal de Saúde, os alunos também estão no Conselho. Então há o envolvimento profissional, político e social do aluno. Ele está junto. Hoje, por exemplo, os alunos me dão retorno da avaliação da saúde no município bem positivo. Eles conseguem ter a clareza, "Isso está certo, isso está errado", qual o melhor caminho. E é através desta convivência (Doc. 3).

Nóvoa (2008) reforça a interação com a comunidade e a situa, no processo pedagógico dos cursos, como um dos pontos fundamentais a ser superado pelos professores. Os docentes nunca aceitaram prestar contas de seu trabalho às comunidades locais, e seu ethos profissional definiuse por "internalização", e não por "externalização" (NÓVOA, 2000, p. 227). Em contrapartida, em nossos dias, todos os discursos insistem na necessidade de os docentes reconstruírem um laço forte com o espaço comunitário. É um dos principais dilemas que eles devem enfrentar.

Retoma-se, aqui, as considerações apresentadas anteriormente sobre o ser "bom professor". No espaço da aula, precisa estar evidenciada a visão geral do professor, não só do conteúdo a ser ensinado, mas também desse conteúdo na realidade. Concomitantemente, Tardif (2002) defende que a prática pedagógica, através da aprendizagem, de um ambiente favorável a ela e até do próprio domínio do conteúdo, leva a entender que o saber pedagógico é de suma importância para o saber específico da 
disciplina. Assim, afirma que é verdade que "o conhecimento pedagógico do conteúdo a ser ensinado não pode ser separado do conhecimento desse conteúdo" (TARDIF, 2002, p. 120).

Considerando o que colocam o PPPI e os projetos pedagógicos dos cursos, é possível ter presente a aula como espaço da pesquisa, porque vai buscar, nas vivências cotidianas, elementos que se constituem em possibilidades de investigação e, assim, construir o conhecimento, que depois poderá ser estendido e difundido na comunidade, pela extensão.

As atividades desenvolvidas em sala de aula são implicadas pela atuação do professor e do acadêmico. O desenvolvimento da aula acontece com muita rapidez, num ritmo que impõe ao professor uma atenção constante, manifestada na sua capacidade de ler a trama da aula, fazendo articulação com o tempo disponível e com a linguagem, de acordo com o nível de conhecimento da turma, e ainda manter o interesse do estudante. É nesse espaço escolar que os saberes são organizados e reorganizados, no sentido de atender à demanda da aula. Pode-se observar essas questões pelo depoimento dos professores expostos no Quadro:

\section{Quadro 5 - Depoimentos: atividades desenvolvidas em aula}

"[...] costumo variar as atividades propostas para que as aulas não fiquem exaustivas" (Doc. 1).

"[...] procuro dinamizar junto com os alunos, apresento a proposta e peço sugestões. Normalmente, divido em aulas expositivas, trabalhos em grupos, simulações, dinâmicas" (Doc. 3).

“[...] organizo assuntos teóricos e práticos pertinentes a disciplina" (Doc. 5).

"[...] tempo de exposição, contextualização, discussão, fechamento do conteúdo" (Doc. 8).

Fonte: Dados da pesquisa

Está sob a responsabilidade do professor a organização da aula; portanto, ela constitui importante espaço de autonomia dos docentes. Ao se constituir como espaço de autonomia, gera comprometimento ético e profissional, atitude da qual emerge a compreensão sobre seu trabalho. 
São juízos de valor que mobilizam e que articulam os saberes utilizados na prática, dando significado às necessidades da turma. Ressalta-se aqui o encaminhamento que Doc. 9 dá ao seu trabalho de aula: “As minhas aulas hoje são muito mais voltadas para a necessidade o aluno. É claro, eu entendo que o aluno tem que ter um conhecimento mínimo na área, mas eu olho muito para ele e procuro observar a forma com que ele consegue aprender" (Doc. 9).

Para garantir o compromisso do olhar atento, de perceber as necessidades dos alunos, de considerar a diversidade e de acompanhar o processo de aprendizagem, o docente faz uma reflexão constante sobre sua prática pedagógica. Nesse contexto, vale manifestar que a aula protagonizada de forma reflexiva, democrática, participativa, comprometida com a aprendizagem apresenta indicadores inovadores da prática pedagógica (CUNHA, 2006), visto que tanto docentes quanto estudantes precisam exercitar o pensar crítico/criativo/independente/ competente, visando dar sentido, identificar e resolver os problemas complexos do cotidiano de sala de aula e da instituição. Esse exercício de prática requer envolver a comunidade acadêmica do curso na perspectiva da construção dos saberes pedagógicos/didáticos orientadores e organizadores da prática e de sua relação com os diversos saberes.

A universidade, em sua perspectiva de prestar um serviço público de educação, independentemente do seu caráter privado, tem por finalidade efetivar, através da docência e da investigação, vários aspectos da ciência, do conhecimento e da tecnologia em prol do desenvolvimento cultural, social e econômico da sociedade. Nesse sentido:

O professor ao entrar na sala de aula para ensinar uma disciplina não deixa de ser um cidadão, alguém que faz parte de um povo, de uma nação, que se encontra em um processo histórico e dialético, participando da construção da vida e da história de seu povo (MASETTO, 2003b, p. 31).

O professor precisa ter uma visão de homem, de mundo, de sociedade, de cultura, de educação, e dirigir suas opções e suas ações mais ou menos conscientemente. Ele é um cidadão, um político, alguém compromissado com seu tempo, com sua civilização e com sua comunidade, e isso não 
se descola de sua pele no instante em que entra em sala de aula.

Como cidadão, o professor estará aberto para o que se passa na sociedade, fora da universidade ou faculdade, suas transformações, evoluções, mudanças; atento para as novas formas de participação, as novas conquistas, os novos valores emergentes, as novas descobertas, novas proposições visando inclusive abrir espaço para discussão e debate com seus alunos sobre tais aspectos na medida em que afetem a formação e o exercício profissional (MASETTO, 2003b, p. 31-32)

O autor sugere que a reflexão crítica e sua adaptação ao novo, de forma criteriosa, são fundamentais para o professor compreender como se pratica e como se vive a cidadania nos tempos atuais, buscando formas de inserir esses aspectos em suas aulas, tratando sobre os diversos temas, selecionando textos de leitura, escolhendo estratégias que, ao mesmo tempo, permitam ao acadêmico adquirir informações, reconstruir seu conhecimento, debater aspectos cidadãos que envolvam o assunto e manifestar suas opiniões a respeito disso. Conciliar o técnico com o ético, na vida profissional, é fundamental tanto para o professor quanto para o estudante.

Dessa forma, essas competências do professor formador, tratadas pelos autores, são conjuntos de saberes significados por esses professores, oriundos de diversos momentos do seu percurso profissional.

Diante dos posicionamentos extraídos das entrevistas com os professores, e sabendo-se que o cotidiano acadêmico é o lócus em que se adquire a experiência docente, é necessário que se ofereçam condições para que o professor possa desenvolver uma prática condizente àquilo que se defende. Isso passa pelas condições de trabalho oferecidas.

Ser professor, para os docentes pesquisados, é contribuir para a formação do futuro profissional; é orientar o acadêmico a pensar, a refletir, a raciocinar e a se informar sobre a área do conhecimento relacionada à disciplina; é ter responsabilidade; é ter conhecimento e saber transmiti-lo; é ser afetivo, ser um profissional.

A análise do ser professor mostra que os pesquisados assumem posicionamentos em relação à sua prática docente; colocam-se como colaboradores na formação do futuro profissional, orientadores dos 
estudantes, responsáveis pela formação, detentores do conhecimento e com capacidade de transmissão, auxiliares na produção do conhecimento. Nesse sentido, pode-se conceber a sala de aula como uma comunidade de aprendizagem em que existem relações recíprocas entre docente e acadêmico e, destes, entre si, em torno da aprendizagem.

Cada docente desenvolve uma concepção própria sobre como os alunos aprendem. Essa concepção pode considerar ou não os processos individuais na construção do conhecimento e, dessa forma, romper ou não abordagens teóricas que predominavam no passado, segundo as quais todos os acadêmicos aprendem da mesma forma.

É necessário salientar a importância de os professores participarem da vida da universidade, do seu dia a dia, e de entenderem que a autonomia que lhes é dada não se limita só à sala de aula, mas ao contexto da organização da instituição (cursos e Centro), no qual se abrem possibilidades para reflexões coletivas, enfrentamento de ideias e organização do espaço de trabalho. Essas condições sociais e históricas, nas quais se exerce a profissão docente, devem ser consideradas, porque servem de base para a prática geradora de saberes, que são situados em contextos, como indica Tardif (2002).

A sala de aula é a oportunidade de confrontar teorias e práticas, de reafirmar tradições pedagógicas consagradas, por serem significativas; permite pensar, repensar, construir novos saberes. As dificuldades relatadas pelos professores, muitas vezes, estão imbricadas ao fato de que, no cotidiano do ofício de ser professor, vários condicionantes surgem nas situações concretas da sala de aula.

Com base nas falas dos professores, é possível constatar que a sala de aula é um espaço de referência, lócus privilegiado de experiências e saberes. É um espaço de contradições entre teorias e práticas, de relações entre professores e estudantes, e do encontro do professor consigo mesmo. Essa tensão entre os limites e as possibilidades constitui o educador no dia a dia, considerando-se que essa realidade não para, é contínua, é mutável; e pode desvelar a identidade, transformando e reafirmando marcas e traços do ser docente.

A gestão da aula é um grande desafio, tendo em vista que cada turma, 
a cada ano, apresenta características diferentes, realidades diferenciadas. A mudança é, portanto, algo necessário na construção do ser professor, de modo que possa levá-lo a compreender que ela é condição sine qua non para melhorar as práticas existentes, visando à melhoria da qualidade da educação. Isso indica que a mudança serve para transformar e para construir outros caminhos e saberes indispensáveis à ação do educador sobre o seu saber/fazer educativo.

\section{Nas considerações: possibilidades geradas}

A reflexão sobre a prática do professor, realizada sob o ponto de vista da indissociabilidade do ensino, da pesquisa e da extensão, a partir da análise das dificuldades e das facilidades, da relação professorestudante e da referencialidade do bom professor, como uma ação que vai se construindo no cotidiano da aula e da universidade, desnudou questões interessantes. No diálogo entabulado durante a entrevista entre entrevistador e entrevistado, algumas questões que iam sendo respondidas, ao mesmo tempo, eram reavaliadas, e os professores saíam dali com outros propósitos, pois, ao verbalizarem as questões que estavam sendo encaminhadas, tinham a possibilidade de refletir sobre essa prática e de perceber outros caminhos que poderiam seguir no seu cotidiano institucional.

A partir das falas, percebeu-se que, entre as dificuldades encontradas no início da carreira, se evidenciam a preparação das aulas, o colocar-se com postura de professor e a comunicação como elementos facilitadores e fundamentais no processo de ensino/aprendizagem.

O trabalho realizado, tendo presente a indissociabilidade entre ensino, pesquisa e extensão, apesar do esforço dos professores em fundamentarem as práticas nessa perspectiva, ainda é um longo caminho a ser percorrido pelos docentes da instituição.

Na trajetória apresentada por eles, destaca-se a importância da sua relação com os acadêmicos e da referencialidade do bom professor, pela possibilidade de favorecer o processo de construção do conhecimento. Nesse sentido, a comunicação, o saber como agir em determinadas situações, o conhecimento, o respeito e a motivação são referenciais que 
integram a prática pedagógica do professor.

Portanto, fica evidente que os saberes pessoais, pedagógicos, experienciais, fazem parte da prática dos professores, e, pela ação/ reflexão/ação das vivências em sala de aula, é possível melhorar e avançar nas mudanças necessárias. Da mesma forma, possibilitam que o acadêmico construa conhecimentos, e que tais conhecimentos façam sentido à sua vida prática, podendo intervir como cidadão na sociedade que aí se apresenta.

Os saberes necessários à prática docente são indispensáveis à vida do educador, de forma que esse possa desempenhar seu trabalho a partir de uma práxis educativa comprometida com o saber/fazer docente. Essa práxis requer (se a pós-graduação não se apresenta como obrigatoriedade) que a instituição de ensino superior apresente como obrigatória a formação em serviço, na qual a prática pedagógica seja a tônica dominante. Isso pode ser feito pela Pedagogia Universitária, cuja discussão sobre o exercício da ação docente no lócus em que atua pode levá-los a trilhar caminhos que visualizem o ensino, a pesquisa e a extensão como um trabalho integrado à vida e à sociedade.

\section{Referências}

CHIZZOTTI, Antonio. Pesquisa em Ciências Sociais. 5. Ed. São Paulo: Cortez, 2004.

CUNHA, Maria I. da. Ensino como mediação da formação do professor universitário. In: MOROSINI, Marília (Org.). Professores do Ensino Superior: identidade, docência e formação. Brasília: INEP, 2000. p. 45-51.

A universidade, desafios políticos e epistemológicos. In: CUNHA, Maria I. da. Pedagogia Universitária: energias emancipatórias em tempos neoliberais. Araraquara, SP: Junqueira \& Marin, 2006. p. 13-19.

CUNHA, Maria Isabel da. O campo da Pedagogia Universitária: legitimidades e desafios para a profissionalização docente. São Leopoldo, RS: Unisinos, 2008a. (Paper). 
FREIRE, Paulo. Pedagogia da autonomia: saberes necessários à prática educativa. São Paulo: Paz e Terra. 1997.

MASETTO, M. T. (Org.). Docência na universidade. Campinas, SP: Papirus, 1998.

. Docência na universidade: repensando a aula. In: TEODORO, A.; VASCONCELOS, Maria L. (Org.). Ensinar e aprender no ensino superior: por uma epistemologia da curiosidade na formação universitária. São Paulo: Cortez, 2003b.

NÓVOA, Antonio. Os professores e o "novo" espaço público da educação. In: TARDIF, M. LESSARD, C. (Org.). Trad. Lucy Magalhães. O ofício de professor: história, perspectivas e desafios internacionais. Petrópolis, RJ: Vozes, 2008. p. 217-233.

(Org.). Profissão professor. Porto: Porto Editora, 1992.

UNIVERSIDADE DE CRUZ ALTA. Projeto Pedagógico do Curso de Farmácia. Cruz Alta, RS: Unicruz, 2012.

UNIVERSIDADE DE CRUZ ALTA. Projeto Político-Pedagógico Institucional. Cruz Alta, RS: Unicruz, 2007.

PIMENTA, Selma G.; ANASTASIOU, Lea das G. C. Docência no Ensino Superior. São Paulo: Cortez, 2002.

TARDIF, Maurice. Saberes e formação profissional. Petrópolis, RJ: Vozes, 2002.

VEIGA, Ilma P. A. Projeto Político-Pedagógico da escola: uma construção coletiva. In: VEIGA, Ilma P. A. (Org.). Projeto Político-Pedagógico da escola: uma construção possível. Campinas, SP: Papirus, 2004. p. 11-35.

Recebido em 03/06/2015 Aprovado em 21/06/2016 